\title{
A novel technique for stent dysfunction after endoscopic ultrasound-guided hepaticogastrostomy with antegrade stenting
}

Recently, endoscopic ultrasound-guided hepaticogastrostomy (EUS-HGS) has been developed as a new drainage technique for malignant biliary obstruction; however, a high adverse event rate has been reported [1]. Stent migration is a serious adverse event. The use of long stents in EUS-HGS is therefore recommended to prevent this complication

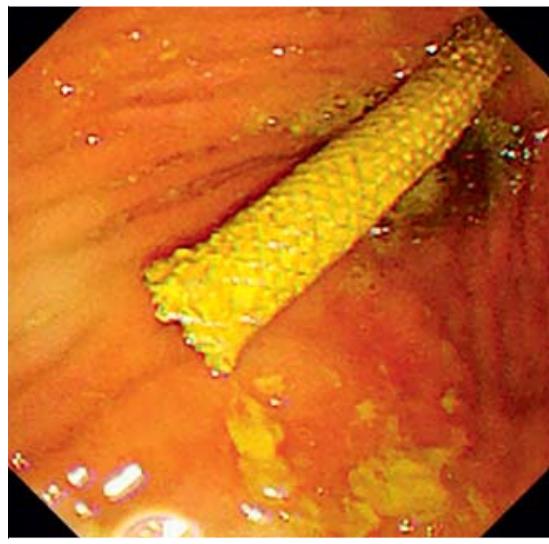

- Fig. 1 Gastroscopy showing the endoscopic ultrasound-guided hepaticogastrostomy stent. A 5-cm length of the originally deployed $8 \times 100-\mathrm{mm}$ covered metal stent was seen in the gastric lumen.

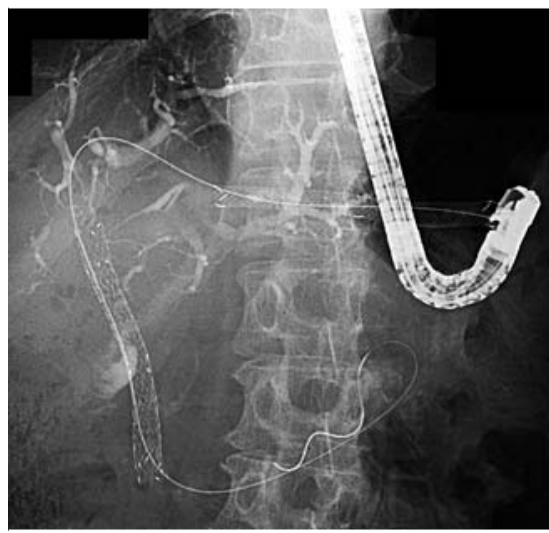

- Fig. 2 Radiographic image showing a 0.025-inch guidewire that was advanced through both the endoscopic ultrasoundguided hepaticogastrostomy and antegrade stents, and was successfully passed via the ampulla into the duodenum.
[2]. However, when a long stent is placed in the gastrointestinal lumen, re-intervention at the time of stent dysfunction can be challenging; several re-intervention techniques have been reported [2 4]. We present a case using a successful simple re-intervention technique for stent dysfunction after EUS-HGS combined with antegrade stenting.

A 67-year-old man with advanced gastric cancer presented with a recurrence of jaundice 6 months after undergoing EUS-HGS combined with antegrade stenting for distal biliary obstruction. An $8 \times 100-\mathrm{mm}$ covered metal stent had been deployed during EUS-HGS ( Fig. 1).

Because his cholangitis was classified as moderate according to the Tokyo Guideline [5], urgent biliary drainage was attempted. First, a therapeutic duodenoscope was advanced to the EUS-HGS
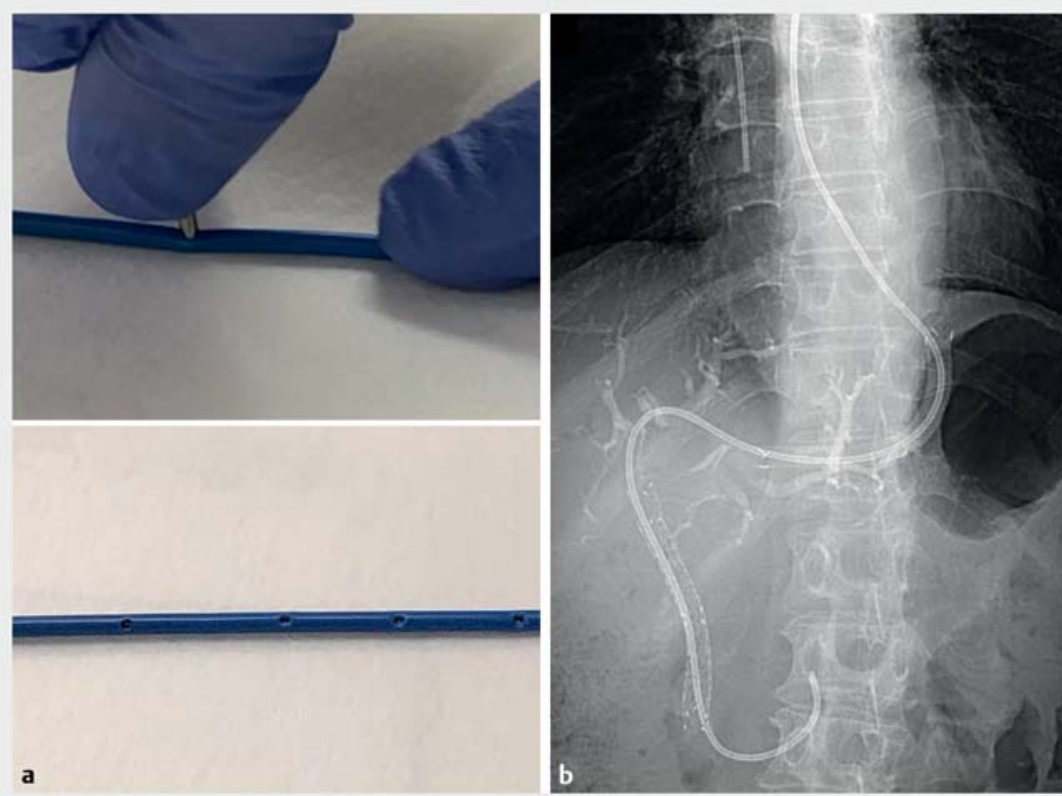

site. Second, a guidewire was advanced through the EUS-HGS and antegrade stents; it was successfully passed via the ampulla into the duodenum ( $\triangleright$ Fig.2). Finally, a 6-Fr endoscopic nasobiliary drainage (ENBD) tube (Flexima; Boston Scientific, Marlborough, Massachusetts, USA) that had been self-adjusted with side holes opened with a hole puncher up to $25 \mathrm{~cm}$ from the tip was placed through the HGS and antegrade stents with its tip located in the duodenum ( Fig.3). The patient's cholangitis resolved within a few days. A week after the procedure, the ENBD tube was cut in the gastric lumen using a loop cutter (Olympus, Tokyo, Japan) for internalization ( $\triangleright$ Fig. 4 ; $\triangleright$ Video 1 ).

Currently, $>6$ months have passed, and the patient is continuing chemotherapy without stent dysfunction. This novel reintervention technique is simple and

- Fig. 3 The self-adjusted endoscopic nasobiliary drainage (ENBD) tube: a consisting of commercially available 6-Fr ENBD tube into which side holes were opened with a hole puncher up to $25 \mathrm{~cm}$ from the tip; $\mathbf{b}$ after placement through the HGS and antegrade stents so that its tip was located in the duodenum. 

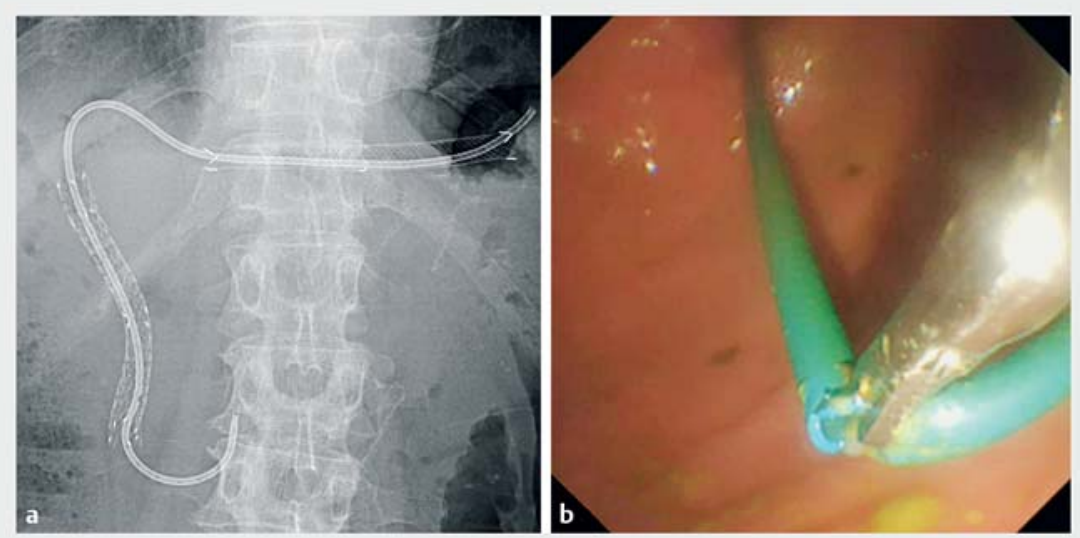

- Fig. 4 The self-adjusted endoscopic nasobiliary drainage tube was cut in the gastric lumen using a loop cutter for internalization, seen on: a fluoroscopic view; b endoscopic view.
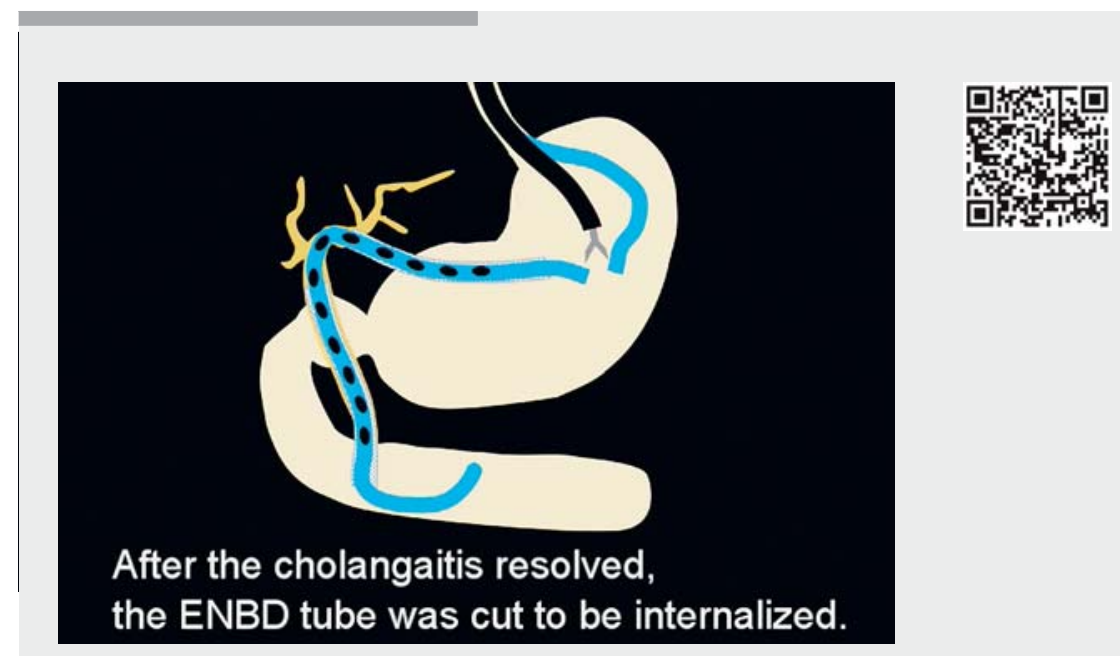

$\nabla$ Video 1 An endoscopic nasobiliary drainage tube self-adjusted with side holes was placed through the hepaticogastrostomy and antegrade stents. After the patient's cholangitis had resolved, the drainage tube was cut in the gastric lumen for internalization.

could be useful for stent occlusion after EUS-HGS combined with antegrade stenting.

Endoscopy_UCTN_Code_TTT_1AR_2AZ

Competing interests

None
Ayana Okamoto, Kosuke Minaga, Mamoru Takenaka, Tomoe Yoshikawa, Ken Kamata, Kentaro Yamao, Masatoshi Kudo Department of Gastroenterology and Hepatology, Kindai University Faculty of Medicine, Osaka-Sayama, Japan
Corresponding author

\section{Kosuke Minaga, MD, PhD}

Department of Gastroenterology and Hepatology, Kindai University Faculty of Medicine, 377-2 Ohno-Higashi, Osaka-

Sayama, 589-8511, Japan

Fax: $+81-72-3672880$

kousukeminaga@med.kindai.ac.jp

\section{References}

[1] Wang K, Zhu J, Xing L et al. Assessment of efficacy and safety of EUS-guided biliary drainage: a systematic review. Gastrointest Endosc 2016; 83: 1218 - 1227

[2] Nakai $\mathrm{Y}$, Isayama $\mathrm{H}$, Yamamoto $\mathrm{N}$ et al. Safety and effectiveness of a long, partially covered metal stent for endoscopic ultrasound-guided hepaticogastrostomy in patients with malignant biliary obstruction. Endoscopy 2016; 48: $1125-1128$

[3] Yane K, Katanuma A, Maguchi $\mathrm{H}$ et al. Successful reintervention with metal stent trimming using argon plasma coagulation after endoscopic ultrasound-guided hepaticogastrostomy. Endoscopy 2014; 46: E391-E392

[4] Minaga K, Takenaka M, Miyata T et al. Through-the-mesh technique after endoscopic ultrasonography-guided hepaticogastrostomy: a novel re-intervention method. Endoscopy 2016; 48: E369-E370

[5] Miura F, Okamoto K, Takada T et al. Tokyo Guidelines 2018: initial management of acute biliary infection and flowchart for acute cholangitis. J Hepatobiliary Pancreat Sci 2018; 25: $31-40$

\section{Bibliography}

DOI https://doi.org/10.1055/a-0890-3220

Published online: 9.5.2019

Endoscopy 2019; 51: E255-E256

(c) Georg Thieme Verlag KG

Stuttgart · New York

ISSN 0013-726X 